\title{
Beaten ballots: political participation dynamics amidst police interventions - CORRIGENDUM
}

Toni Rodon and Marc Guinjoan

(First published online 17 November 2021)

https://doi.org/10.1017/psrm.2020.48. Published by Cambridge University Press 7 January 2021

Keywords: Civil/domestic conflict; ethnicity and nationalism; political participation and turnout; voting behaviour; CORRIGENDUM

In the above article (Rodon, T., \& Guinjoan, M. (2021)) the author Marc Guinjoan's affiliation was incorrectly listed at the time of publication. The affiliation should be;

Marc Guinjoan, Institutions and Political Economy Research Group (IPErG). Universitat de Barcelona.

The affiliation has been updated in the original article.

\section{Reference}

Rodon T and Guinjoan M (2021) Beaten ballots: Political participation dynamics amidst police interventions. Political Science Research and Methods, 1-18. doi:10.1017/psrm.2020.48

\footnotetext{
Cite this article: Rodon T, Guinjoan M (2022). Beaten ballots: political participation dynamics amidst police interventions CORRIGENDUM. Political Science Research and Methods 10, 675-675. https://doi.org/10.1017/psrm.2021.61

(C) The Author(s), 2021. Published by Cambridge University Press on behalf of the European Political Science Association. This is an Open Access article, distributed under the terms of the Creative Commons Attribution licence (http://creativecommons.org/licenses/by/4.0/), which permits unrestricted re-use, distribution, and reproduction in any medium, provided the original work is properly cited.
} 